\title{
Methyl Linderone Suppresses TPA-Stimulated IL-8 and MMP-9 Expression Via the ERK/STAT3 Pathway in MCF-7 Breast Cancer Cells ${ }^{\mathbb{E}}$
}

\author{
Jae-Hwan Yoon ${ }^{1}$, Thu-Huyen Pham ${ }^{1}$, Jintak Lee ${ }^{1}$, Jiyon Lee ${ }^{1}$, Hyung-Won Ryu ${ }^{2}$, Sei-Ryang $\mathrm{Oh}^{2}$, Jae-Wook Oh ${ }^{3 *}$, \\ and Do-Young Yoon ${ }^{1 *}$ \\ ${ }^{1}$ Department of Bioscience and Biotechnology, Research Institute of Bioactive-Metabolome Network; ${ }^{3}$ Department of Stem Cell and \\ Regenerative Biotechnology, Konkuk University, Seoul 05029, Republic of Korea \\ ${ }^{2}$ Natural Medicine Research Center, Korea Research Institute of Bioscience and Biotechnology, Cheongju 28116, Republic of Korea
}

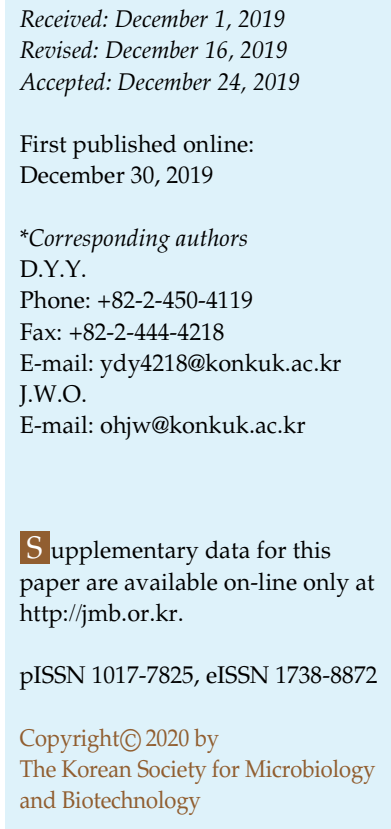

S upplementary data for this paper are available on-line only at http://jmb.or.kr.

pISSN 1017-7825, eISSN 1738-8872

Copyright(C) 2020 by

The Korean Society for Microbiology and Biotechnology

\begin{abstract}
Methyl linderone (ML), a cyclo-pentenedione, was isolated from the fruit of Lindera erythrocarpa Makino (family Lauraceae). This plant has well-known anti-inflammatory effects; however, the anti-cancer effects of ML have not yet been reported. Thus, in the present study we investigated the effects of ML on the metastasis of human breast cancer cells. We used 12O-tetradecanoyl phorbol-13-acetate (TPA)-stimulated MCF-7 cells as the cell model to study the effects of ML on invasion and migration. ML was found to reduce the invasion and migration rate of TPA-stimulated MCF-7 cells. Moreover, it inhibited two metastasis-related factors, matrix metalloproteinase-9 (MMP-9) and interleukin-8 (IL-8), at the mRNA and protein expression levels, in TPA-treated MCF-7 cells. The mechanism by which ML exerted these effects was through the inhibition of translocation of activator protein-1 (AP-1) and signal transducer and activator of transcription-3 (STAT3), mediated via phosphorylation of extracellular signal-regulated kinase (ERK). Taken together, our findings indicated that ML attenuated the TPA-stimulated invasion and migration of MCF-7 cells by suppressing the phosphorylation of ERK and its downstream factors, AP-1 and STAT3. Therefore, ML is a potential agent for the treatment of breast cancer metastasis.
\end{abstract}

Keywords: Methyl linderone, metastasis, MCF-7 cells, IL-8, MMP-9

\section{Introduction}

Breast cancer is the second most prevalent cause of cancer mortality and the most common gynecological cancer worldwide [1, 2]. In 2018, there were approximately 2 million cases and 627,000 deaths and these numbers are predicted to increase yearly [3]. The breast cancer survival rate has risen recently because of improved diagnosis and treatment with a diverse range of anti-cancer agents. However, mortality rates remain high due to metastasis [4]. The metastatic process begins with cell invasion, which includes degradation of the extracellular matrix (ECM) and changes in cell adhesion, cell interactions, and inherent tissue structure [5]. The ECM is composed of collagen, elastin, and fibronectin, and it can be degraded by extracellular proteinases, such as matrix metalloproteinases (MMPs), which are metastasis-related factors in breast cancer [6, 7]. MMPs are a family of proteolytic enzymes consisting of zinc-dependent endopeptidases. They have been reported to be involved in rheumatoid arthritis and metastasis [8, 9]. The MMP family is divided into six subclasses: matrilysines (MMP-7 and -26), membranebound MMPs (MMP-14, -15, -16, -17, -24, and -25), stromalysines (MMP-3, -10, and -11), collagenases (MMP-1, $-8,-13$, and -18), gelatinases (MMP-2 and -9), and an unclassified group [10]. Among the various MMP groups, MMP-2 (gelatinase-A) and -9 (gelatinase-B) are the key enzymes associated with metastasis and invasion [11]. Therefore, suppressing MMP-9 expression is a potential approach to control malignant metastasis. Many stimulators, 
such as tumor necrosis factor- $\alpha$, fibroblast growth factor-2, and 12-O-tetradecanoylphorbol-13-acetate (TPA) can induce MMP-9 overexpression [12,13]. Among a variety of stimuli, TPA, as a tumor promoter, has been reported to induce MMP-9 expression by upregulating transcription factors, such as activator protein-1 (AP-1), signal transducer and activator of transcription-3 (STAT3), and nuclear factor kappa B (NF-кB) [14, 15]. TPA has also been shown to activate IL-8 expression and this model is widely used to assess carcinogenesis pathways [16].

Methyl linderone (ML) was initially isolated from the dried fruits of Lindera erythrocarpa Makino (family Lauraceae) [17]. This plant is used as a traditional medicine and is reported to have digestive, anti-bacterial, and antiinflammatory effects [18]. However, the anti-migratory and anti-invasive effects of ML have not yet been fully examined. In this study, we evaluated the anti-metastatic effects and investigated the underlying mechanisms of ML in TPA-stimulated MCF-7 breast cancer cells.

\section{Materials and Methods}

\section{Preparation of ML}

Lindera erythrocarpa fruits were collected from Jeju Island, Korea, in October 2013. A voucher specimen (KRIB 0000372) was deposited in the Herbarium of the Korea Research Institute of Bioscience and Biotechnology (Korea). The target compounds were isolated from dried fruits of L. erythorocarpa as previously described [19]. Detailed information on the isolation procedure can be found in the Supplementary Material. Briefly, the extracts (770.0 $\mathrm{g}$, yield $15.4 \%)$ were fractionated on a silica gel column (10 $\times 90 \mathrm{~cm}$, JEO prep 60, 40-63 $\mu \mathrm{m}, 2.3 \mathrm{~kg}$ ) and eluted using hexaneethyl acetate mixtures $(20: 1 \rightarrow 15: 1 \rightarrow 10: 1 \rightarrow 8: 1 \rightarrow 6: 1 \rightarrow 4: 1 \rightarrow 2: 1 \rightarrow 1: 1)$ to give 10 pooled fractions. In fraction $8, \mathrm{ML}$ was purified and identified by nuclear magnetic resonance (NMR); ultravioletvisible spectrophotometry (UV); mass spectrometry (MS); and MS/MS, using high-resolution MS spectral data (HRMS).

\section{Reagents}

The stock solution of ML (100 mM) in dimethyl sulfoxide was stored in the dark at $4^{\circ} \mathrm{C}$ and then diluted in Dulbecco's modified Eagle's medium (DMEM; Hyclone, USA) immediately before use. The CellTiter 96 AQueous One Solution Cell Proliferation Assay reagent (3-[4,5-dimethylthiazol-2-yl]-5-[3-carboxymethoxyphenyl]2-[4-sulfophenyl]-2H-tetrazolium [MTS]) was obtained from Promega (USA). NE-PER Nuclear and Cytoplasmic Extraction Reagents were supplied from Thermo Fisher Scientific (USA). RIPA buffer was obtained from DyneBio (Korea). The ERK inhibitor, PD98059, and antibodies specific for p-ERK, ERK, pJNK, JNK, p-p38, NF-кB p65, c-Jun, c-Fos, STAT3, and PARP were purchased from Cell Signaling Technology (USA). The horseradish peroxidase-conjugated anti-rabbit IgG and anti-mouse $\operatorname{IgG}$ secondary antibodies were purchased from Millipore Sigma (USA). Antibodies specific for GAPDH, p38, and NF-кB were obtained from Santa Cruz Biotechnology (USA).

\section{Cell Lines}

The human breast adenocarcinoma cell line, MCF-7, was obtained from the American Type Culture Collection (USA). Cells were cultured in DMEM containing $10 \%(\mathrm{v} / \mathrm{v})$ heat-inactivated fetal bovine serum (Millipore Sigma) at $37^{\circ} \mathrm{C}$ in an atmosphere of $5 \% \mathrm{CO}_{2}$.

\section{Cell Viability Assays}

Cell viability was assessed using an MTS assay, according to the manufacturer's instructions. Cells $\left(1 \times 10^{3}\right.$ cells/well $)$ were seeded in 96-well plates and then treated with various concentrations of ML and TPA $(50 \mathrm{nM})$ for $24 \mathrm{~h}$. Absorbance was measured at $492 \mathrm{~nm}$ using a microplate reader (Apollo LB 9110; Berthold Technologies, Germany).

\section{Cell Migration Assays}

For migration assays, cells $\left(6 \times 10^{6}\right.$ cells $\left./ \mathrm{ml}\right)$ were seeded onto the upper chambers (Corning Inc., USA) in DMEM without serum and treated with ML for $2 \mathrm{~h}$. To the lower chamber, $750 \mu \mathrm{l}$ of TPAtreated serum-free DMEM $(50 \mathrm{nM})$ was then added. After incubation for $24 \mathrm{~h}$, non-migrated cells were removed from the chamber. Migrated cells were stained with a Diff-Quik Solution kit (Sysmex, Japan). The number of migrated cells was assessed using a microscope. Cells were then dissolved in $10 \%$ acetic acid $(100 \mu \mathrm{l})$ and colorimetrically measured at $620 \mathrm{~nm}$.

\section{Cell Invasion Assays}

For invasion assay, cells $\left(6 \times 10^{6}\right.$ cells $\left./ \mathrm{ml}\right)$ were seeded onto upper chambers coated with $20 \mu$ of Matrigel in DMEM without serum and then treated with ML for $2 \mathrm{~h}$. To the lower chamber, $750 \mu$ of TPA-treated serum-free DMEM $(50 \mathrm{nM})$ was then added. After incubation for $24 \mathrm{~h}$, non-invading cells were removed from the chamber. Invading cells were stained with a Diff-Quik Solution kit and were quantified using a microscope. The cells were then dissolved in 10\% acetic acid (100 $\mu \mathrm{l})$ and colorimetrically measured at $620 \mathrm{~nm}$.

\section{Gelatin Zymography}

For gelatin zymography, cells $\left(1 \times 10^{5}\right.$ cells/well) were seeded in 12-well plates and incubated until fully grown. After an overnight incubation, cells were pretreated with ML for $2 \mathrm{~h}$ and then treated with TPA $(50 \mathrm{nM})$ for $24 \mathrm{~h}$. Forty microliters of culture supernatant was loaded on $10 \%$ SDS-polyacrylamide gels containing $0.1 \%$ gelatin. Gels were stained with InstantBlue (Millipore Sigma) for $1 \mathrm{~h}$ in the dark. Areas of gelatinolytic degradation were observed on the dark blue background. 


\section{Western Blotting Analysis}

Cells were treated with various ML concentrations for $2 \mathrm{~h}$ and then with TPA for $24 \mathrm{~h}$. They were then harvested and lysed in RIPA buffer containing a protease inhibitor cocktail (Roche Diagnostics, Germany). The nuclear and cytoplasmic components were fractionated using NE-PER Nuclear and Cytoplasmic Extraction Reagents, according to the manufacturer's instructions. The protein content of the extracts was quantified using the Bradford assay (BioRad, USA). Cell lysates were separated by $10-$ $15 \%$ SDS polyacrylamide gel electrophoresis. The proteins were then transferred onto polyvinylidene difluoride membranes (Millipore Sigma), which were blocked in $5 \%$ powdered skim milk, in Tris-buffered saline containing $0.1 \%$ Tween-20, for $1 \mathrm{~h}$ at RT. Membranes were then incubated overnight at $4^{\circ} \mathrm{C}$ with specific primary antibodies. After washing, the membranes were incubated with secondary antibodies for $1 \mathrm{~h}$ at room temperature. The results were visualized using a chemiluminescence detection kit (Advanstar, USA).

\section{qRT-PCR}

Cells were incubated for $24 \mathrm{~h}$ and then treated with various concentrations of ML for $2 \mathrm{~h}$ and with TPA (50 nM) for $24 \mathrm{~h}$. Cells treated with ML were harvested and RNA was extracted using an easy-BLUE Total RNA Extraction Kit (Intron Biotechnology, Korea), according to the manufacturer's instructions. cDNA was reverse transcribed from the RNA samples using M-MuLV reverse transcriptase (New England Biolabs, USA). qPCR was evaluated using the SensiFAST SYBR NO-ROX Kit (Bioline, UK) and a Rotor-Gene 6000 series thermal cycler (software v1.7; Qiagen, Germany). Each sample contained one of the following primer sets: MMP-9, 5'- AATCTCACC GACAGGCAGCT-3' (forward), 5' - CCAAACTGGATGACGTGTC-3' (reverse); IL-8, 5' CTTGGCAGCCTTCCTGATTT-3' (forward), 5'- CTCAGCCCTC TTCAAACT-3' (reverse); or GAPDH, 5' - TGATGACATCAAGAA GGTGGT-3' (forward), 5'- TCCTTGGAGGCC TGT AGGCC-3' (reverse).

\section{Statistical Analysis}

Data are presented as means $\pm \mathrm{SD}(n=3)$. One-way analysis of variance, followed by Tukey's HSD test, were used to evaluate differences between groups. Values of $p<0.05$ or $<0.01$ were considered statistically significant.

\section{Results}

\section{Effects of ML on MCF-7 Cell Viability}

The non-cytotoxicity of ML on MCF-7 cells was assessed using an MTS assay, in the presence or absence of TPA (50 nM) for $24 \mathrm{~h}$. The results showed that ML did not affect the viability of MCF-7 cells up to a concentration of $10 \mu \mathrm{M}$ (Fig. 1). Therefore, non-cytotoxic concentrations of ML up to $10 \mu \mathrm{M}$ were used in subsequent experiments, to study its anti-invasive and anti-migratory effects.
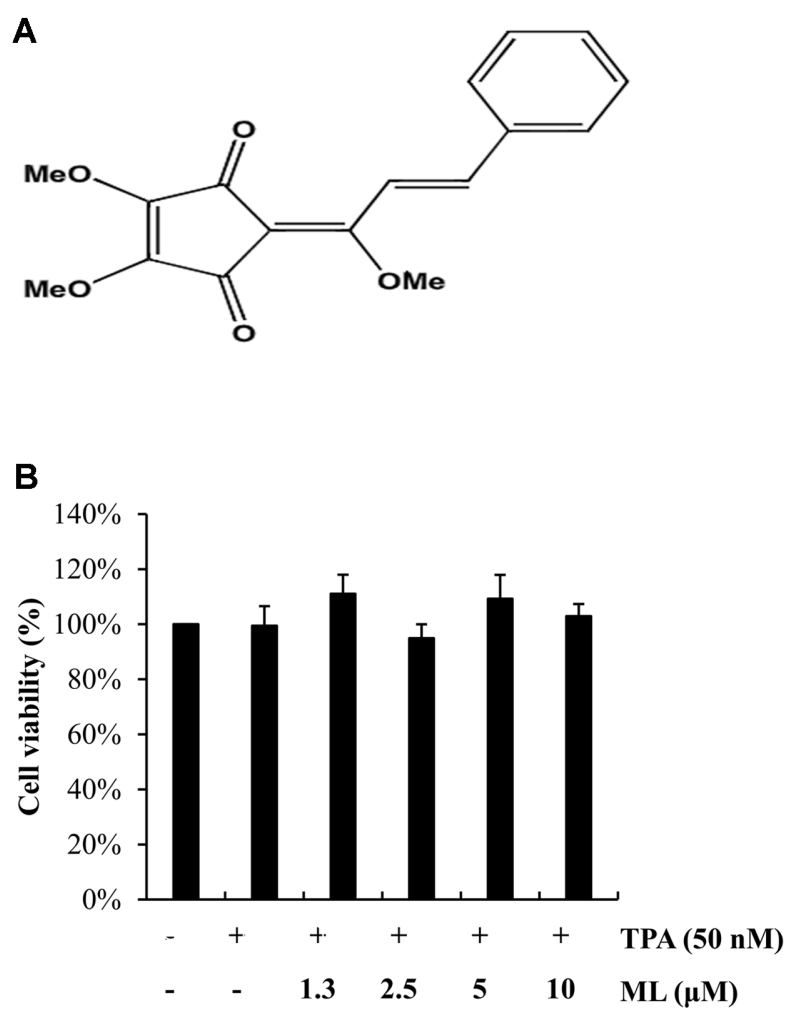

Fig. 1. Chemical structure and cytotoxic effect of methyl linderone on TPA-stimulated MCF-7 cells.

(A) Chemical structure of methyl linderone (ML). MW $=300.0997$ $\left(\mathrm{C}_{17} \mathrm{H}_{16} \mathrm{O}_{5}\right)$. (B) MCF-7 cells were pretreated with $1.3,2.5,5$, or $10 \mu \mathrm{M}$ ML for $2 \mathrm{~h}$. After pretreatment, cells were treated with TPA (50 nM) in the presence or absence of ML. Cell viability was assessed using an MTS assay. Results represent the mean \pm SD of three experiments.

\section{Effects of ML on the Invasion and Migration of TPA-} Stimulated MCF-7 Cells

To evaluate whether ML had anti-metastatic properties, MCF-7 cells were pre-treated with ML for $2 \mathrm{~h}$ and then with TPA for $24 \mathrm{~h}$. Invasion and migration rates were then assessed using Matrigel invasion and migration assays. As shown in Fig. 2, TPA-stimulated cell migration was inhibited by ML in a dose-dependent manner. Moreover, ML attenuated the invasion of TPA-stimulated MCF-7 cells (Fig. 2).

\section{Effect of ML on MMP-9 Expression in TPA-Stimulated MCF-7 Cells}

To elucidate whether ML could inhibit TPA-stimulated MMP-9 and IL-8 expression in MCF-7 cells, their mRNA expression levels were assessed by qRT-PCR. MMP-9 and IL-8 mRNA levels decreased with ML treatment, in a dosedependent manner (Fig. 3). Moreover, the zymography 

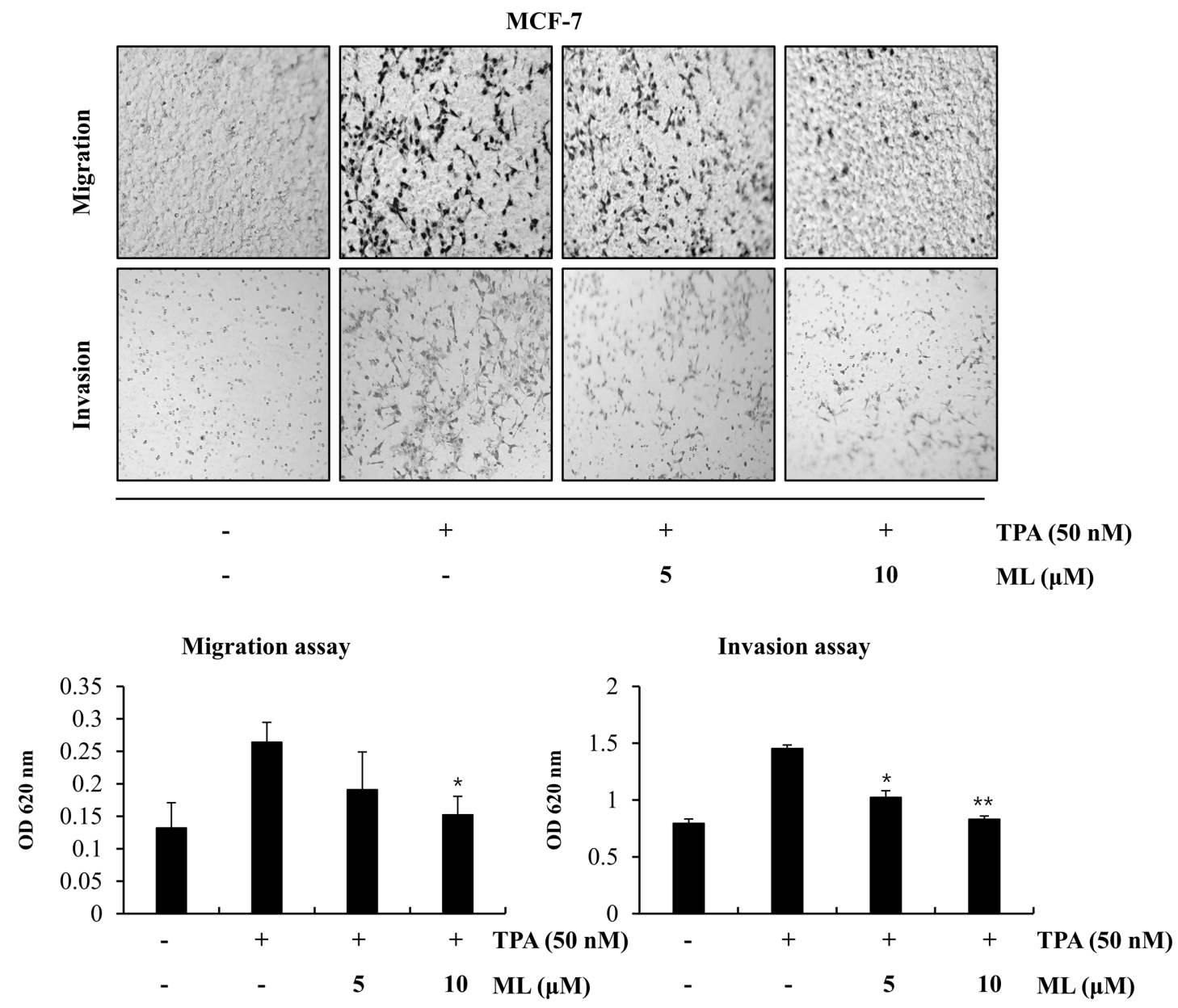

Fig. 2. Effects of ML on breast cancer cell migration and invasion.

For migration assays, MCF-7 cells, without Matrigel, were pretreated with ML at the indicated concentrations and then treated with TPA (50 nM). For invasion assays, cells, with Matrigel, were treated with ML and TPA $(50 \mathrm{nM})$. Results represent the mean \pm SD of three experiments (TPA alone vs. TPA plus ML, $\left.{ }^{*} p<0.05,{ }^{* *} p<0.01\right)$.

results indicated that the enzymatic activity of MMP-9, which was induced by TPA treatment, was suppressed by ML in MCF-7 cells. As shown in Fig. 3, these results demonstrated that ML inhibited the enzymatic activity of MMP-9 and MMP-9 and IL-8 mRNA expression levels under TPA-stimulated conditions in MCF-7 cells.

\section{Effect of ML on ERK/MAPK in TPA-Stimulated MCF-7 Cells}

Next, we assessed whether ML could affect MAPK signaling pathway factors, including ERK, JNK, and p38, which are involved in the regulation of the metastasisrelated factors, IL-8 and MMP-9. TPA treatment was found to increase the phosphorylation of $\mathrm{p}-38, \mathrm{JNK}$, and ERK (Fig. 4). Only the phosphorylation of ERK was inhibited by ML in a dose-dependent manner, while the phosphorylation of JNK and p38 were not affected by ML (Fig. 4). Thus, TPA-stimulated phosphorylation of ERK was the target of ML in MCF-7 cells.

\section{Effects of ML on Nuclear Translocation of Transcription Factors}

The expression of metastasis-related factors is affected by specific transcription factors. Therefore, to examine the effect of ML on the translocation of transcription factors, nuclear fractionation experiments were performed. The nuclear translocation of AP-1 (including c-Jun and c-Fos subunits) and STAT3 was found to be suppressed by ML in TPA-treated MCF7 cells (Fig. 5). The ERK inhibitor, PD98059, was used to confirm that ERK was the upstream regulator of STAT3 and AP-1 in the ML-triggered signaling pathway. ML was found to have similar inhibitory effects 
A

\begin{tabular}{ccccc}
\hline- & + & + & + & $\operatorname{TPA}(50 \mathrm{nM})$ \\
- & - & 5 & 10 & $\operatorname{ML}(\mu \mathrm{M})$
\end{tabular}
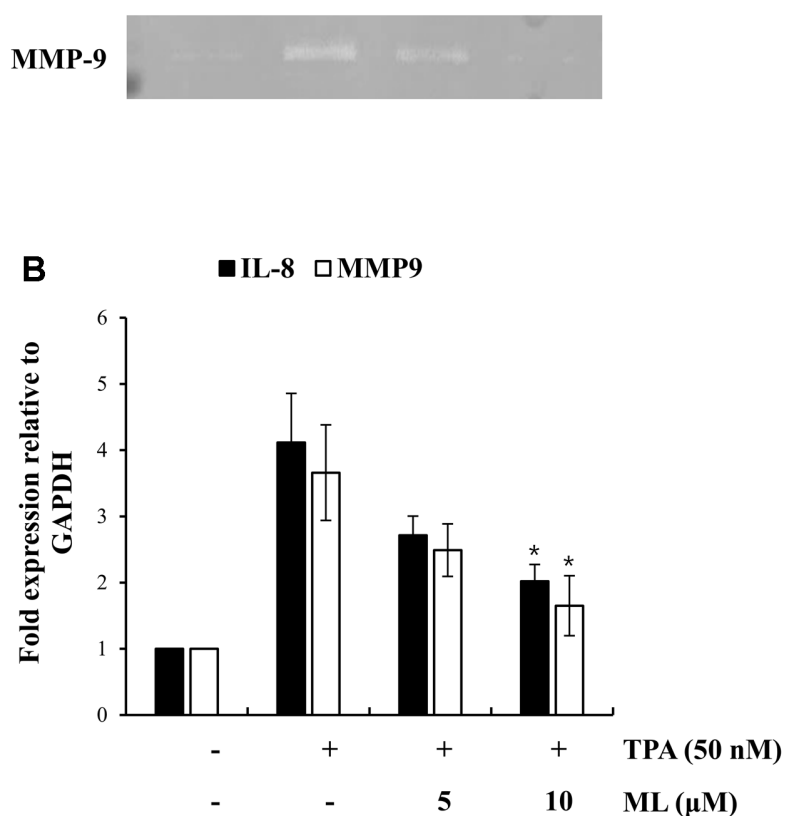

Fig. 3. Effects of ML on MMP-9 activity and the mRNA expression of $I L-8$ and MMP-9.

Cells were pretreated with ML ( 5 or $10 \mu \mathrm{M}$ ) for $2 \mathrm{~h}$ and then with TPA $(50 \mathrm{nM})$ for $24 \mathrm{~h}$. MMP-9 activity after TPA stimulation was assessed using gelatin zymography (A). mRNA expression of $I L-8$ and MMP-9 was assessed by RT-qPCR (B). Results represent the mean \pm SD of three experiments (TPA alone vs. TPA plus ML, ${ }^{*} p<0.05$ ).

as PD98059, on the TPA-stimulated nuclear translocation of AP-1 and STAT3 (Fig. 6A). Furthermore, IL-8 and MMP-9 mRNA expression was inhibited in cells pre-treated with PD98059 or ML, prior to TPA-treatment (Fig. 6B). These data showed that ML attenuated MMP-9 and $I L-8$ expression by suppressing the ERK signaling pathway.

\section{Discussion}

ML has been reported to regulate inflammation by suppressing nitric oxide synthesis, a mediator of acute inflammation, and to suppress the proliferation of H-rastransformed rat-2 cells [17, 20]. However, the regulatory effects of ML on metastasis have not yet been fully demonstrated in human breast cancer. Therefore, we sought to evaluate in the current study whether ML could modulate the metastasis-related factors, IL-8 and MMP-9, to regulate the migration and invasion of breast cancer cells. Furthermore, the underlying mechanism by which

\begin{tabular}{lllll}
\hline- & + & + & + & $\operatorname{TPA}(50 \mathrm{nM})$ \\
- & - & 5 & $\mathbf{1 0}$ & $\operatorname{ML~}(\mu \mathrm{M})$
\end{tabular}

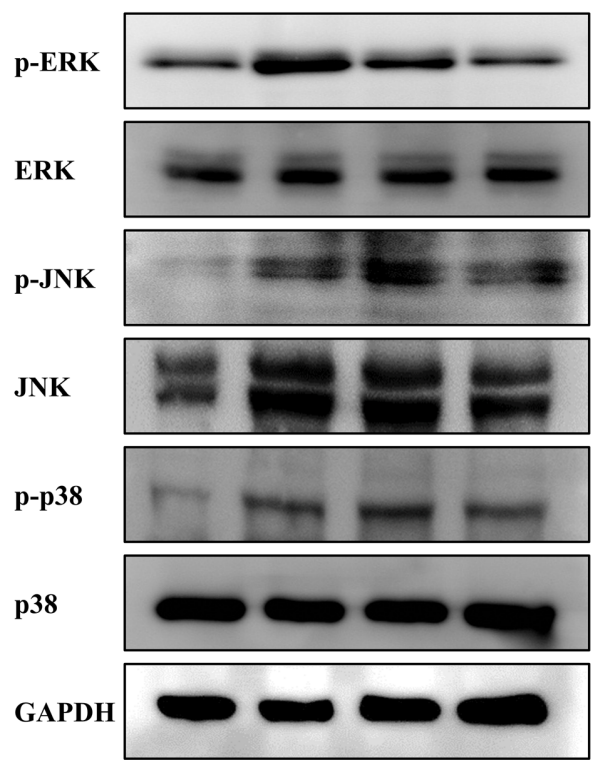

Fig. 4. Effect of ML on MAP kinase in TPA-stimulated breast cancer cells.

MCF cells were pretreated with ML ( 5 or $10 \mu \mathrm{M})$ and then with TPA $(50 \mathrm{nM})$ for $24 \mathrm{~h}$. Western blotting analyses of p-ERK, p-JNK, and pp38 were performed using whole-cell lysates.

ML may act in TPA-stimulated MCF-7 cells was investigated.

Metastasis is the leading cause of cancer-related mortality and it occurs frequently in breast cancer [21]. Tumor metastasis is complex and involves multiple processes, including ECM proteolytic degradation, cell invasion, and cell migration, resulting in cancer growth at the metastatic site [10]. MMP-9 is an important component of the basement membrane and has important functions in tissue recovery. However it can also support the metastatic features of cancer cells, helping them become motile and invasive [22, 23]. Previous studies have demonstrated the expression and activity of MMP-9 in a variety of human cancer cells, including breast cancer cells [23, 24]. Thus, targeting MMP-9 expression is a potential strategy to regulate tumor metastasis. In the present study, the TPAstimulated migration and invasion of MCF-7 cells were inhibited by ML, via the suppression of MMP-9 expression and activity. IL-8, known as neutrophil chemotactic factor, also plays a key role in metastasis and is reported to be overexpressed in breast cancer cells after TPA treatment [16]. In the present study, ML was found to inhibit $I L-8$ expression in TPA-stimulated MCF-7 cells. These results confirmed that ML has potential anti-metastasis effects by 


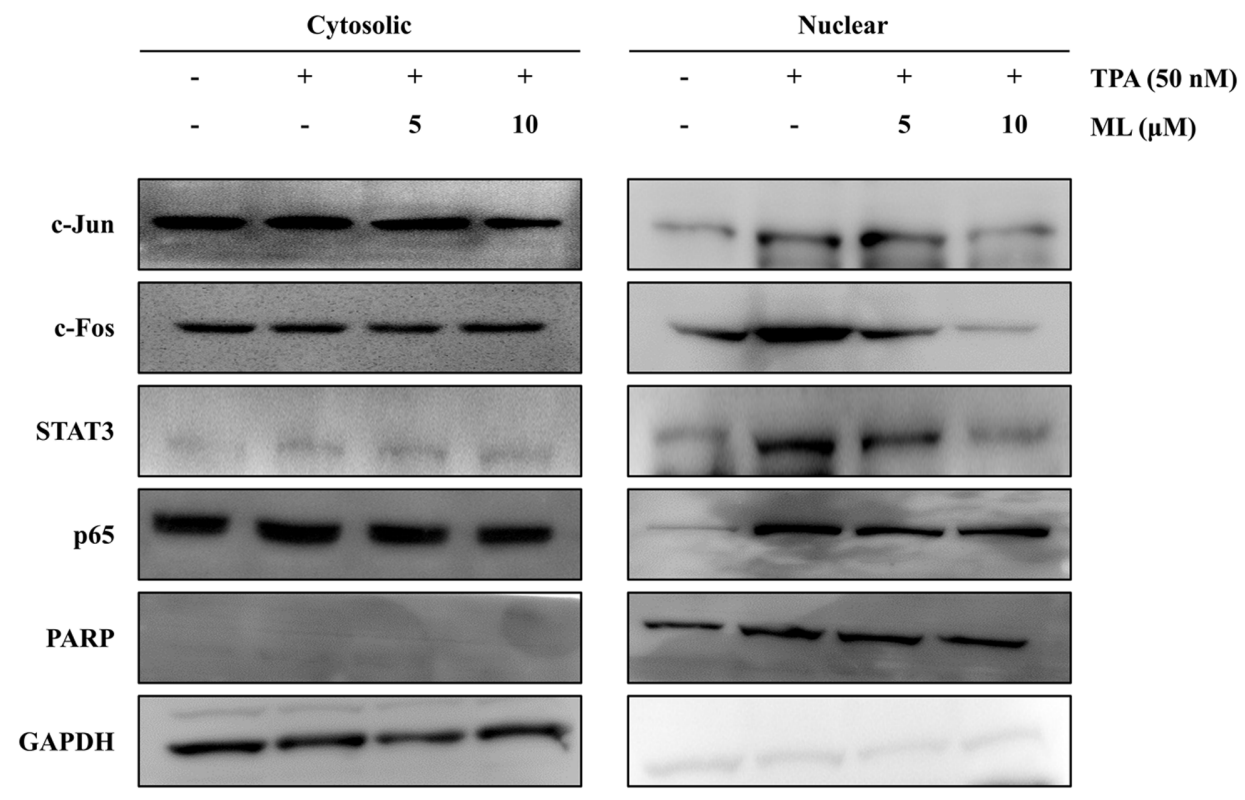

Fig. 5. Effect of ML on transcription factors in TPA-stimulated MCF-7 cells.

MCF-7 cells were pretreated with ML for $2 \mathrm{~h}$ and then treated with TPA. After $24 \mathrm{~h}$ of incubation, AP-1 and STAT3 levels were evaluated in nuclear and cytosolic fractions. The translocation of these factors was detected using specific antibodies. PARP and GAPDH were used as internal controls.

A

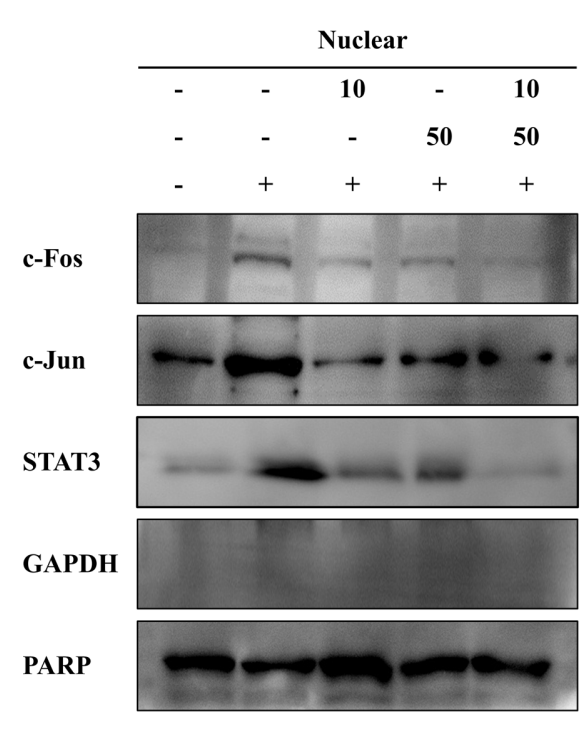

B
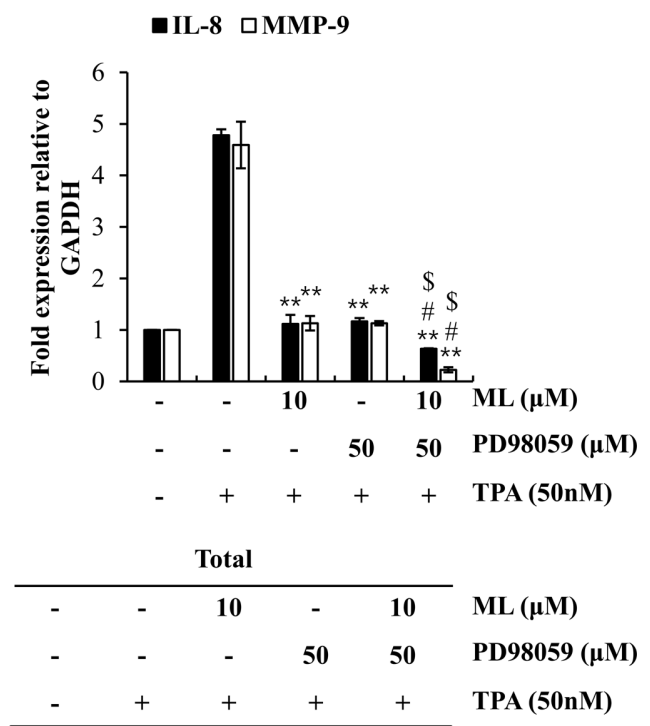

C

p-ERK

GAPDH

ML $(\mu \mathrm{M})$

PD98059 $(\mu \mathrm{M})$

TPA (50nM)

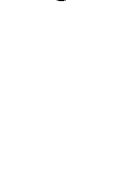

Fig. 6. Effect of ML on the metastasis-related factor, ERK.

MCF-7 cells were pretreated with ML in the presence or absence of the ERK inhibitor, PD98059 $(50 \mu \mathrm{M})$, for $2 \mathrm{~h}$. After incubation, cells were treated with TPA for $24 \mathrm{~h}$. Nuclear transcription factors were assessed by nuclear fractionation and western blotting (A). IL-8 and MMP-9 mRNA expression levels were evaluated by qRT-PCR (B). p-ERK levels were evaluated by western blotting (C). Results represent the mean \pm SD of three experiments (TPA alone vs. TPA plus ML or PD98059, ${ }^{* *} p<0.01$; TPA plus ML vs. TPA plus ML and PD98059, \# $p<0.05$; TPA plus PD98059 vs. TPA plus ML and PD98059, $\$ p<0.05)$. 
reducing MMP-9 and IL-8 levels.

To assess the detailed mechanism underlying the antimetastatic effects of ML, various transcription factors were investigated, including AP-1, STAT3, and NF-kB, which are known to be modulators of $I L-8$ and MMP-9 transcription $[14,25]$. The TPA-stimulated nuclear translocation of AP-1 and STAT3 was attenuated by ML, suggesting that AP-1 and STAT3 are the main transcription factors involved in the signaling pathway regulated by ML. Moreover, MMP-9 and IL- 8 expression has been reported to be modulated by the MAPK family (including ERK, JNK, and p38) via the downstream factors, AP-1 and STAT3 [14, 26]. Therefore, we demonstrated that ML suppressed MMP-9 and IL-8 expression by regulating the ERK signaling pathway.

In conclusion, ML significantly downregulated MMP-9 and IL-8 expression in TPA-stimulated MCF7 cells, by inhibiting the ERK/STAT3/AP-1-mediated signaling pathway. These results suggested that ML is a potential pharmacological agent for breast cancer treatment, to block cancer invasion and migration.

\section{Acknowledgments}

This paper was supported by a National Research Foundation of Korea (NRF) grant funded by the Korean Government (2018R1A2B2001225) and partially the Konkuk University Researcher Fund in 2019.

\section{Conflict of Interest}

The authors have no financial conflicts of interest to declare.

\section{REFERENCES}

1. Torre LA, Bray F, Siegel RL, Ferlay J, Lortet-Tieulent J, Jemal A. 2015. Global cancer statistics, 2012. CA Cancer J. Clin. 65: 87-108.

2. Lee J, Chun HW, Pham TH, Yoon JH, Lee J, Choi MK, et al. 2019. Kanakugiol, a compound isolated from Lindera erythrocarpa, promotes cell death by inducing mitotic catastrophe after cell cycle arrest. J. Microbiol. Biotechnol. [Epub ahead of print]

3. Bray F, Ferlay J, Soerjomataram I, Siegel RL, Torre LA, Jemal A. 2018. Global cancer statistics 2018: GLOBOCAN estimates of incidence and mortality worldwide for 36 cancers in 185 countries. CA Cancer J. Clin. 68: 394-424.

4. Ferlay J, Steliarova-Foucher E, Lortet-Tieulent J, Rosso S, Coebergh JW, Comber H, et al. 2013. Cancer incidence and mortality patterns in Europe: estimates for 40 countries in 2012. Eur. J. Cancer. 49: 1374-1403.

5. Chambers AF, Matrisian LM. 1997. Changing views of the role of matrix metalloproteinases in metastasis. J. Natl. Cancer Inst. 89: 1260-1270.

6. Egeblad M, Werb Z. 2002. New functions for the matrix metalloproteinases in cancer progression. Nat. Rev. Cancer 2: 161-174.

7. Woessner JF, Jr. 1991. Matrix metalloproteinases and their inhibitors in connective tissue remodeling. FASEB J. 5: 21452154.

8. Rosenblum G, Van den Steen PE, Cohen SR, Grossmann JG, Frenkel J, Sertchook R, et al. 2007. Insights into the structure and domain flexibility of full-length pro-matrix metalloproteinase9/gelatinase B. Structure 15: 1227-1236.

9. Ahrens D, Koch AE, Pope RM, Stein-Picarella M, Niedbala MJ. 1996. Expression of matrix metalloproteinase 9 (96-kd gelatinase B) in human rheumatoid arthritis. Arthritis Rheum. 39: 1576-1587.

10. Leber MF, Efferth T. 2009. Molecular principles of cancer invasion and metastasis (review). Int. J. Oncol. 34: 881-895.

11. Ho YL, Li KC, Chao W, Chang YS, Huang GJ. 2012. Korean red ginseng suppresses metastasis of human hepatoma SKHep1 cells by inhibiting matrix metalloproteinase-2/-9 and urokinase plasminogen activator. Evid. Based Complement Alternat. Med. 2012: 965846.

12. Huang Q, Shen HM, Ong CN. 2004. Inhibitory effect of emodin on tumor invasion through suppression of activator protein-1 and nuclear factor-kappaB. Biochem. Pharmacol. 68: 361-371.

13. Song YS, Kim MS, Lee DH, Oh DK, Yoon DY. 2015. 15Hydroxyeicosatetraenoic acid inhibits phorbol-12-Myristate13-Acetate-induced MUC5AC expression in NCI-H292 respiratory epithelial cells. J. Microbiol. Biotechnol. 25: 589-597.

14. Kim SJ, Pham TH, Bak Y, Ryu HW, Oh SR, Yoon DY. 2018. Orientin inhibits invasion by suppressing MMP-9 and IL-8 expression via the PKCalpha/ ERK/AP-1/STAT3-mediated signaling pathways in TPA-treated MCF-7 breast cancer cells. Phytomedicine 50: 35-42.

15. Lee YS, Kim MS, Lee DH, Kwon TH, Song HH, Oh SR, et al. 2015. Luteolin 8-C-beta-fucopyranoside downregulates IL-6 expression by inhibiting MAPKs and the NF-kappaB signaling pathway in human monocytic cells. Pharmacol. Rep. 67: 581587.

16. Wilmer JL, Luster MI. 1995. Chemical induction of interleukin-8, a proinflammatory chemokine, in human epidermal keratinocyte cultures and its relation to cytogenetic toxicity. Cell Biol. Toxicol. 11: 37-50.

17. Oh HM, Choi SK, Lee JM, Lee SK, Kim HY, Han DC, et al. 2005. Cyclopentenediones, inhibitors of farnesyl protein transferase and anti-tumor compounds, isolated from the fruit of Lindera erythrocarpa Makino. Bioorg. Med. Chem. 13: 6182-6187. 
18. Wang SY, Lan XY, Xiao JH, Yang JC, Kao YT, Chang ST. 2008. Antiinflammatory activity of Lindera erythrocarpa fruits. Phytother. Res. 22: 213-216.

19. Lee SH, Oh HW, Fang Y, An SB, Park DS, Song HH, et al. 2015. Identification of plant compounds that disrupt the insect juvenile hormone receptor complex. Proc. Natl. Acad. Sci USA 112: 1733-1738.

20. Surh YJ, Chun KS, Cha HH, Han SS, Keum YS, Park KK, et al. 2001. Molecular mechanisms underlying chemopreventive activities of anti-inflammatory phytochemicals: downregulation of COX-2 and iNOS through suppression of NFkappa B activation. Mutat. Res. 480-481: 243-268.

21. DeSantis CE, Ma J, Goding Sauer A, Newman LA, Jemal A. 2017. Breast cancer statistics, 2017, racial disparity in mortality by state. CA Cancer J. Clin. 67: 439-448.

22. Chen IS, Chang CT, Sheen WS, Teng CM, Tsai IL, Duh CY, et al. 1996. Coumarins and antiplatelet aggregation constituents from Formosan Peucedanum japonicum. Phytochemistry 41: 525-530.
23. Noh EM, Park YJ, Kim JM, Kim MS, Kim HR, Song HK, et al. 2015. Fisetin regulates TPA-induced breast cell invasion by suppressing matrix metalloproteinase- 9 activation via the PKC/ROS/MAPK pathways. Eur. J. Pharmacol. 764: 79-86.

24. Scorilas A, Karameris A, Arnogiannaki N, Ardavanis A, Bassilopoulos P, Trangas T, et al. 2001. Overexpression of matrix-metalloproteinase-9 in human breast cancer: a potential favourable indicator in node-negative patients. Br. J. Cancer 84: 1488-1496.

25. Hwang JK, Yu HN, Noh EM, Kim JM, Hong OY, Youn HJ, et al. 2017. DHA blocks TPA-induced cell invasion by inhibiting MMP-9 expression via suppression of the PPARgamma/NF-kappaB pathway in MCF-7 cells. Oncol. Lett. 13: 243-249.

26. Lin CW, Hou WC, Shen SC, Juan $\mathrm{SH}, \mathrm{Ko} \mathrm{CH}$, Wang LM, et al. 2008. Quercetin inhibition of tumor invasion via suppressing PKC delta/ERK/AP-1-dependent matrix metalloproteinase9 activation in breast carcinoma cells. Carcinogenesis 29: 1807-1815. 